\title{
Corrigendum to: Resistance of metallic substrates protected by an organic coating containing glass flakes [Prog. Org. Coat. 68 (2010) 240-243]
}

\author{
J. González-Guzmán, J.J. Santana ${ }^{+}$, S. González and R.M. Souto \\ Department of Physical Chemistry, University of La Laguna, \\ E-38071 La Laguna, Tenerife, Canary Islands, Spain.
}

\begin{abstract}
+ On leave from the Department of Process Engineering, University of Las Palmas de Gran Canaria, Campus Universitario de Tafira, E-35017 Las Palmas de Gran Canaria, Canary Islands, Spain.
\end{abstract}

In the original article a mistake was made during proof edition since the original Figure 5 was not included but Figure 6 is shown twice instead. The correct Figure 5 is presented below.

Figure legend:

Figure 5 - $R_{P O}$ values as a function of exposure time for glass flake containing epoxypolyamine coated specimens. (A) Carbon steel coated with a $60 \mu \mathrm{m}$ film; and (B) galvanized steel coated with a $60 \mu \mathrm{m}$ film. 
Figure 5 - $R_{P O}$ values as a function of exposure time for glass flake containing epoxypolyamine coated specimens. (A) Carbon steel coated with a $60 \mu \mathrm{m}$ film; and (B) galvanized steel coated with a $60 \mu \mathrm{m}$ film.

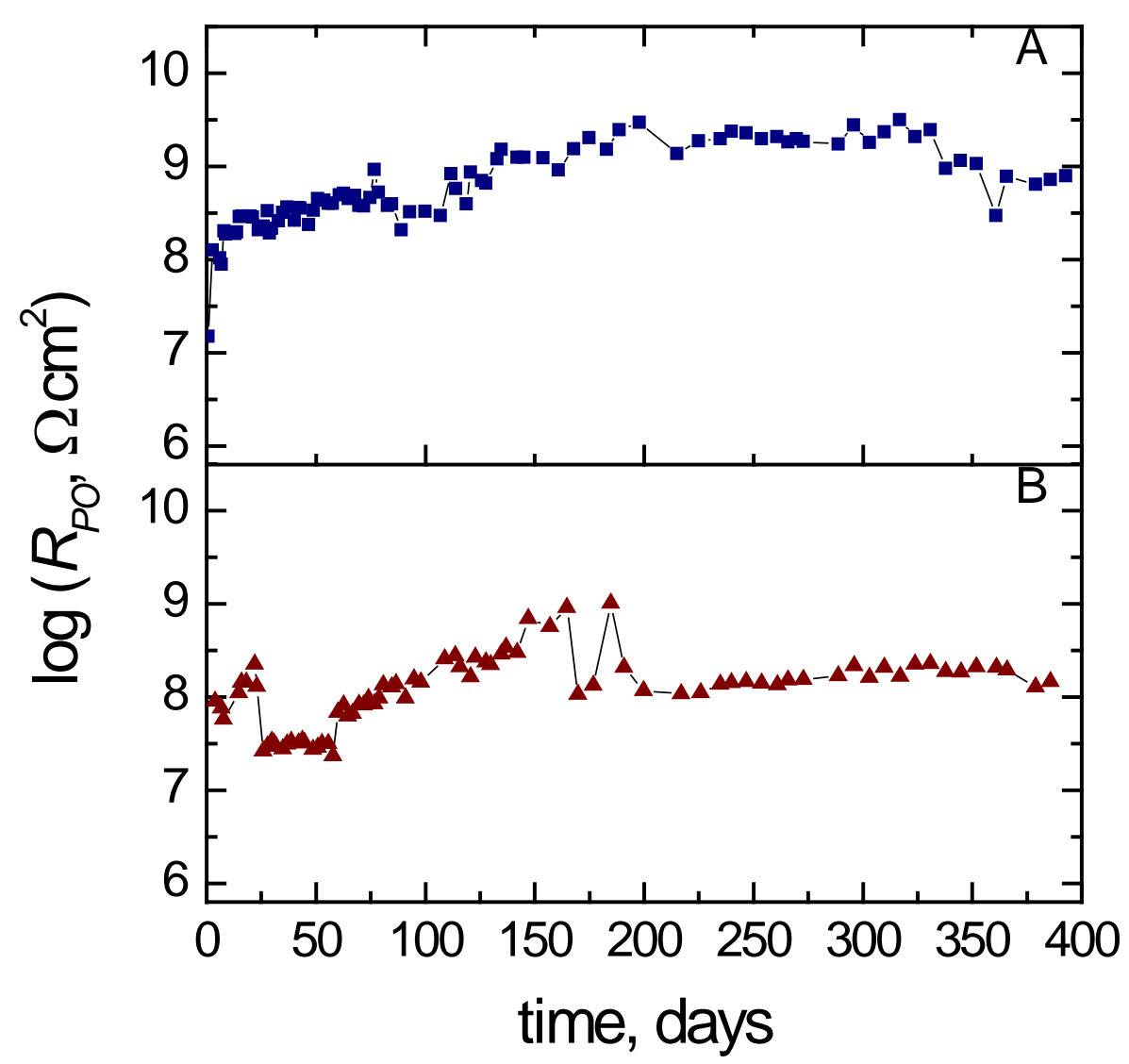

